\title{
Relationship between Lung Function and Hypertension among Rural Canadians using Fractional Polynomials
}

\section{Chandima P Karunanayake ${ }^{1}$, Donna C Rennie ${ }^{1,3}$, Punam Pahwa ${ }^{1,2}$, Yue Chen ${ }^{4}$, and James A Dosman ${ }^{1,5}$}

${ }^{1}$ Canadian Centre for Health and Safety in Agriculture; ${ }^{2}$ Department of Community Health and Epidemiology; ${ }^{3}$ College of Nursing; University of Saskatchewan, Canada; ${ }^{4}$ Department of Epidemiology and Community, Medicine, University of Ottawa, Canada; ${ }^{5}$ Department of Medicine, University of Saskatchewan, Canada.

\section{ABSTRACT}

Studies have shown that persons with lower pulmonary function have a higher risk for developing cardiovascular diseases including hypertension. The objectives of this paper are to examine: (i) the relationship between lung function and hypertension; and (ii) the correct functional forms of the continuous predictors of hypertension using fractional polynomials.

This analysis was based on data from a cross-sectional community study of 1,834 adult subjects aged 18-79 years conducted in 2003 in Humboldt, Saskatchewan, Canada. Clinical measurements were made during a clinic visit, and other information was collected from a questionnaire. Logistic regression analysis was conducted to determine associations between hypertension and lung function measurements. Multivariate fractional polynomial logistic regression model was used to preserve the continuous nature of the predictor variables.

There was an expected significant difference between men and women in values for FVC and $F E V_{1}$. We observed that the ordinary logistic regression model and fractional polynomial model gave the same functional form when stratified by gender. The data suggest an increasing risk of hypertension with decreasing FVC and FEV $V_{1}$ values. After adjusting for potential risk factors including age, body mass index, parental history of hypertension and smoking, there was increased risk of hypertension among women with low FVC [OR adj: 0.73 (95\% CI: 0.56, 
0.95)]. We did not see this association for men [OR adj: 1.10 (95\% CI: 0.90, 1.33)]. We observed that the risk of hypertension increases with decreasing FVC for women after adjusting for potential risk factors.

Key words: Forced vital capacity (FVC), Forced expiatory volume in one second $\left(\mathrm{FEV}_{1}\right)$, Systolic blood pressure (SBP), Diastolic blood pressure (DBP), High blood pressure (HBP), Chronic obstructive pulmonary disease (COPD), Hypertension, Fractional polynomials (FP).

\section{Introduction}

Numerous studies [1-7] have demonstrated that blood pressure is a risk factor for future cardiovascular diseases. Also these studies have shown that persons with lower pulmonary function indicators, forced expiratory volume in one second $\left(\mathrm{FEV}_{1}\right)$ [2,4-5, 8-9], forced vital capacity (FVC) [6-9] and $\mathrm{FEV}_{1} / \mathrm{FVC}$ ratio [3] have a higher risk for developing cardiovascular diseases including hypertension. There may be several possible pathophysiological mechanisms for these associations including impaired left ventricular performance and cigarette smoking. Strachan [5] has suggested that longitudinal study measurements of ventilatory function may assist clinical decisions about whether to treat mild hypertension. Engström et al. [8] found that the incidence of cardiovascular disease and death associated with hypertension is increased in the presence of reduced lung function.

Many studies demonstrated that patients with Chronic Obstructive Pulmonary Disease (COPD) had at least one chronic co-morbidity condition like hypertension, diabetes, coronary artery disease, heart failure, cancer and lung infections in addition to COPD [10-13]. Also, authors of three of these reports hypothesized that COPD was not only a lung disease but also a part of chronic systemic inflammatory syndrome [11-13].

Previous analyses have confirmed that weight gain, alcohol consumption, parental history of hypertension and excessive use of salt are predictive 
factors of developing hypertension [6, 14-16]. In this paper we examined: (i) the relationship between lung function measures (FVC and $\mathrm{FEV}_{1}$ ) and hypertension in a Canadian rural population; and (ii) the correct functional forms of the continuous predictors for hypertension.

\section{Methods}

A cross-sectional community study of adults was conducted in 2003 in Humboldt, Saskatchewan, Canada. The study population included all town residents. This analysis was based on the data from adult subjects aged 18-79 years. The participants were identified by means of a community canvass as previously described [17] that invited each eligible subject to participate in the project and to provide a written consent for clinical studies including spirometry and blood pressure assessment. If the subjects were not willing to participate in the clinical testing, the reasons for nonparticipation were identified. All participants brought completed questionnaires to a health screening centre located in the community. Of the 2897 adults who were eligible for the study, 2090 persons (909 men and 1181 women) completed the questionnaire and attended the health clinic, yielding an overall response rate of $71.0 \%$. For this analysis, 1834 participants had complete information on lung function and blood pressure.

The questionnaires were self-administered and elicited information on socio-demographic factors, smoking, alcohol consumption, home environment, individual and family history of pulmonary and cardiovascular diseases and diabetes. Each participant had a clinic visit that included measurements of lung function, blood pressure, height and weight. Guidelines for blood pressure measurements were those recommended by the Canadian Coalition for High Blood Pressure [18]. Standard mercury sphygmomanometers and 15 inch stethoscopes were used. Appropriately sized blood pressure cuffs were used based on subjects' arm circumference: regular adult cuff $(22-23 \mathrm{~cm})$, large adult cuff $(33-41 \mathrm{~cm})$ and thigh cuff $(>41 \mathrm{~cm})$. Prior to blood pressure reading, each subject rested quietly for a minimum of 5 minutes. Two blood pressure readings were obtained and the mean of the two measurements was used for this analysis. Weight was measured to the nearest $0.1 \mathrm{~kg}$ 
using a calibrated hospital spring scale with subjects dressed in normal indoor clothing but without shoes. Height was measured in centimeters against a wall, using a fixed tape measure and head square, with subjects standing in stocking feet on a hard surface.

Chen et al [19] reported that subjects tended to underreport high blood pressure (HBP) for a self reported HBP question. Therefore, in this study we defined hypertension as a combination of self-reported and measured HBP together with current medication use for HBP. Hypertension was defined as systolic blood pressure (SBP) $\geq 140 \mathrm{~mm} \mathrm{Hg}$ or diastolic blood pressure (DBP) $\geq 90 \mathrm{~mm} \mathrm{Hg}$, or a positive response the self-reported question "has a doctor ever said you had HBP?", or a report of current use of anti-hypertensive medication.

BMI was calculated as weight $(\mathrm{kg}) /$ height $(\mathrm{m})^{2}$ and was based on objectively measured information. Pulmonary function tests were conducted using a MedGraphics CPF-S system spirometer (Medical Graphics Corp. St. Paul, MN 55127, 1992), according to American Thoracic Society criteria [20]. Forced vital capacity (FVC [L]) and forced expiratory volume in one second $\left(\mathrm{FEV}_{1}[\mathrm{~L}]\right)$ were used in the current analysis.

Smoking status was established as "yes" if there was a report of smoking in the past year or no report of current smoking and a past history of smoking at least 20 packs; otherwise smoking status was coded as "no". Current alcohol consumption was categorized into groups of none, less than 1 day per week, 1 day per week, 2 days per week, and 3 or more days per week. Due to lack of information on amount of alcohol currently used and questionable reliability of the response, alcohol consumption was not included into the statistical models and was only presented descriptively.

Parental history of high blood pressure was determined by a positive response to any of the following: "Has (did) your biological father had (have) high blood pressure?" or "Has (did) your biological mother had (have) high blood pressure?". 
Subjects signed a witnessed informed consent. Prior to the study, approval by the Biomedical Research Ethics Board of the University of Saskatchewan was obtained.

Descriptive statistics were expressed as mean \pm standard deviation (SD) or percentage. Differences in continuous and categorical variables were examined by two-independent sample t-tests and chi-squared tests, respectively. Logistic regression analysis was conducted to determine associations between hypertension and lung function measurements after adjusting for age, body mass index, parental history of blood pressure, and smoking. Statistical analyses were performed using STATA (STATA Corp LP, Texas, USA). In order to investigate associations between hypertension and lung function testing variables adjusting for important covariates, univariate analysis was conducted to determine candidate variables for the multivariable model [21]. Variables with pvalue $<0.20$ were selected for the multivariable logistic regression analysis. Multivariate fractional polynomial logistic model was used to preserve the continuous nature of the predictor variables.

Fractional polynomials (FPs) are a flexible family of parametric models proposed by Royston [22-24]. It is possible to fit one (FP1), two (FP2) or more $(\mathrm{FPm})$ power transformations of the form $X^{p}$, where the exponent(s) $\boldsymbol{p}$ being chosen from a small, predefined set $S=\{-2,-1,-0.5,0$, $0.5,1,2,3\}$ and $X^{0}$ denotes $\log \mathrm{X}$. An FP function with two terms (FP2) is a model $\beta_{1} X^{p_{1}}+\beta_{2} X^{p_{2}}$ with exponents' $p_{1}$ and $p_{2}$. For $p_{1}=p_{2}=p$ (repeated powers), FP2 is defined as $\beta_{1} X^{p}+\beta_{2} X^{p} \log X$. These models provide 8 FP1 functions (including linear) and 36 FP2 functions. More than two terms are rarely required in practical applications. The multivariate fractional polynomial model is useful when it is desirable to preserve the continuous nature of the predictor variables when most or all of the relationships are non-linear. When there are several continuous variables, fractional polynomial transformation for each of predictor should be performed in turn, while holding the fractional forms of the other predictors temporarily fixed. The algorithm converges when the 
fractional forms of the predictors do not change. It is possible to select the best fitted model according to deviance $\mathrm{D}$, where $\mathrm{D}=-2 \times \log$ likelihood. Royston [22] recommended that it is convenient to use the deviance $\mathrm{D}(1,1)$ associated with the straight line model as a baseline for reporting the deviances of other models. The gain $(G)$ for a given model with $m$ degree and powers of $\boldsymbol{p}$ can be defined as follows: $G=D(1,1)$ $\mathrm{D}(m, \boldsymbol{p})$. A larger gain indicates a better model fit. The best model was selected using above criteria.

\section{Results}

There were 1834 individuals (798 men and 1036 women) in the study. Mean age was $50.9( \pm \mathrm{SD}=15.6)$ years. Of the 1834 participants, 967 persons $(52.7 \%$ ) had hypertension (only $26 \%$ of participants self-reported high blood pressure and only $19.6 \%$ were on treatment for high blood pressure). There were significant difference between those with and without hypertension in the distribution of age, body mass index, gender, alcohol consumption and lung function values. Participants with hypertension had a higher proportion of parental history of hypertension compared to participants without hypertension (Table 1).

There was a lower proportion (46\%) of high blood pressure in women compared to men $(61.4 \%)$, but more women $(22.3 \%)$ were taking antihypertensive medication compared to men $(16.0 \%)$. Women had a higher proportion of parental history of hypertension compared to men.

Multivariate logistic regression models (model 1 and model 2) were fitted to determine the relationship between hypertension and lung function (FVC and $\mathrm{FEV}_{1}$ ) adjusting for covariates (Table 2). FVC and $\mathrm{FEV}_{1}$ values were plotted against the residuals to evaluate the goodness of fit of the models graphically (Figure 1 and Figure 2, respectively). Multivariate fractional polynomial logistic regression models (model 3 and model 4) were fitted after adjusting for covariates. For both $\mathrm{FVC}$ and $\mathrm{FEV}_{1}$ the best fitted model was a second degree fractional polynomial with powers $(2$, 2) (Table 3 and Table 4 respectively) and the functional form (two terms) of the lung function would be $X^{2}+X^{2} \log X$. Results are shown in Table 5 . 
Residual plots for FVC and $\mathrm{FEV}_{1}$ are shown in Figure 3 and Figure 4, respectively. Comparison of four figures (Figure 1-4), indicates that fractional polynomial provides a better functional form compared to linear relationship of lung function values $\mathrm{FVC}$ and $\mathrm{FEV}_{1}$.

Next a stratified analysis by gender was performed because our descriptive analysis indicates that lung function measures were smaller for females compared to males and there was significant difference in lung function values between males and females ( $p<0.0001$ for both FVC and $\left.\mathrm{FEV}_{1}\right)$. An ordinary logistic regression model and fractional polynomial model were fitted to the stratified data. In this case the same linear forms of lung function $\left(\mathrm{FVC}\right.$ and $\left.\mathrm{FEV}_{1}\right)$ were seen for both fractional polynomial and ordinary logistic regression models. Results of stratified analysis of the relationship between hypertension and lung function was given in Tables 6 and 7. Table 6 shows an increasing risk of hypertension with decreasing pulmonary function $\mathrm{FVC}$ and $\mathrm{FEV}_{1}$ values for both males and females before adjustment for covariates. After adjusting for age, body mass index, parental history of hypertension and smoking, lower FVC was significantly associated with a higher risk of hypertension in women but not in men and there was no significant association between $\mathrm{FEV}_{1}$ and hypertension. Also we observed that older age and higher BMI were significantly related to an increased risk of hypertension in both sexes. Parental history of blood pressure was significantly related to hypertension of women participants.

\section{Discussion}

In most regression analysis continuous predictors such as lung function variables are included into the model as a linear term. However, in some situations the relationship with outcome and predictor is not linear, but can be a polynomial form. Therefore it is important to examine the functional form of continuous predictors. In this study both lung function measures $\left(\mathrm{FVC}\right.$ and $\left.\mathrm{FEV}_{1}\right)$ had a fractional polynomial $(2,2)$ functional form. Age and BMI had a linear form after adjusting for other covariates. However, the functional form for the lung function variables varied with 
gender and the linear functional form of lung function variables fits better to the data when stratified by gender.

There is a strong relationship between hypertension and cardiovascular diseases [1, 25-26]. Although lung function is inversely related to risk of cardiovascular disease, the mechanism of observed associations particularly by gender remains unclear. Our study reveled that lower FVC was associated with the prevalence of hypertension in women but not in men.

Several recent studies have shown similar results of the relationship between lung function and hypertension after adjusting for potential confounders [9, 12, 27-28]. Schnabel et al. [9] reported that high blood pressure was associated with reduced lung function (for both $\%$ predicted $\mathrm{FVC}$ and $\mathrm{FEV}_{1}$ ) in general adult population adjusting for gender and other covariates. In contrast to our study, Margretardottir et al [12] found that significantly stronger inverse association between FVC and hypertension in men than in women. Few longitudinal associations [6, 7, $28,29]$ between lung function and incidence of hypertension have been reported. Sparrow et al. [7] and Selby et al. [6] reported a significant association between FVC and the incidence of hypertension. A study from the People's Republic of China [28] reported weaker associations between lung function (For both $\mathrm{FVC}$ and $\mathrm{FEV}_{1}$ ) and incidence of hypertension among men and women. But significant inverse association was observed only for women. Engström et al. [29] reported that blood pressure increase was inversely related to lung function for men 55 to 68 years of age.

The reasons for the association between reduced lung function and hypertension are not known. It is possible that left ventricular failure causes pulmonary vascular engorgement and interstitial oedema, which may reduce the compliance of the lungs and then result in lower values for FVC. Another possible explanation is the confounding effect of age, since blood pressure increases with age and lung function decreases. Therefore, we adjusted our analysis for age. One other possibility is that 
cigarette smoking is a common risk factor for both lung function and hypertension. As demonstrated in other studies [6, 28, 30] cigarette smoking was not associated with risk of hypertension among the population that we studied. Another possibility is that antihypertensive medications could affect the lung function test values. It has been shown [31] that Atenolol, an antihypertensive medication resulted in significant decline of $\mathrm{FVC}$ and $\mathrm{FEV}_{1}$, whereas antihypertensive agents such as Amlodipine did not show any significant change on pulmonary parameters. In our study, we did not have the sufficient information about specific drugs taken needed to further evaluate the affect of various drugs used to treat hypertension on lung function.

Previous studies have been identified other risk factors for hypertension such as physical inactivity, higher BMI, excessive salt intake, smoking and alcohol consumption [8, 19, 28, 12, 32-33]. Chen et al. [19] reported that the relationship between obesity and hypertension was stronger in the younger subjects than in the older subjects. We therefore adjusted for BMI and found that for both men and women, BMI is a significant risk factor for hypertension. In a previous study [34] parental history of hypertension appeared to be a predictor of future hypertension only in women, and our study provided consistent results.

Identification and control of raised blood pressure is currently the main strategy for prevention of stroke and heart failure. Therefore measurements of FVC and $\mathrm{FEV}_{1}$ may be more or just as useful as are certain other conventional cardiovascular risk factors currently used to guide clinical decisions about the management of patients with mild hypertension $[5,35]$.

Fabbri and Rabe [10] conclude that clinical practice guidelines in general seem to ignore the fact that most patients with a chronic disease have additional co-morbidities. Recognizing the possibility of comorbities as suggested by the chronic systemic inflammatory syndrome may lead to better overall management of chronic diseases and their influence 
systemically [10]. Gender differences also need to be taken into account when examining co-morbid conditions.

\section{Conflicts of interest}

No financial or other potential conflict of interest exists for any of the authors.

\section{Acknowledgement}

This study was supported by a grant from the Canadian Institutes of Health Research (Grant no: MOP-57907) and the NIH intramural research program. We would also like to express our appreciation to the people of Humboldt, Saskatchewan, Canada for their cooperation with the study, and to members of the local organizing committees, for their assistance with the study.

Table 1: Frequencies (\%) and means (standard deviation) for 1834 participants with and without hypertension and other covariates

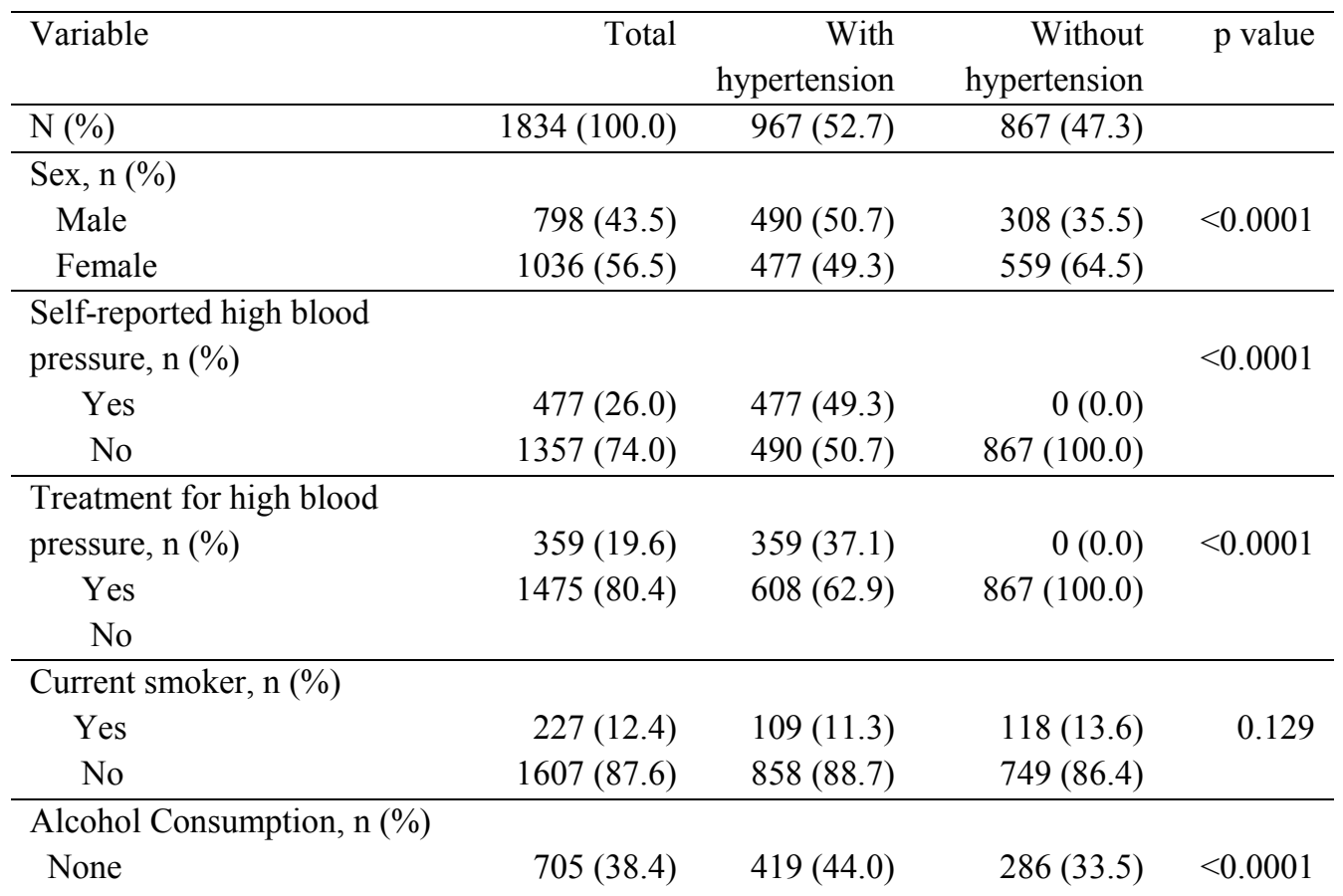




\begin{tabular}{|c|c|c|c|c|}
\hline$<1$ day per week & $224(12.2)$ & $92(9.7)$ & $132(15.4)$ & \\
\hline 1 day per week & $448(24.4)$ & $199(20.9)$ & $249(29.1)$ & \\
\hline 2 days per week & $246(13.4)$ & $128(13.4)$ & $118(13.8)$ & \\
\hline $\begin{array}{l}3 \text { or more days per week } \\
\text { Missing }(n=26)\end{array}$ & $185(10.1)$ & $115(12.1)$ & $70(8.2)$ & \\
\hline \multicolumn{5}{|l|}{$\begin{array}{l}\text { Parental history of } \\
\text { hypertension, } \mathrm{n}(\%)\end{array}$} \\
\hline Yes & $869(47.4)$ & $493(51.0)$ & $376(43.4)$ & 0.001 \\
\hline No & $965(52.6)$ & $474(49.0)$ & $491(56.6)$ & \\
\hline Age (years) & $50.9(15.6)$ & $56.7(14.5)$ & $44.6(14.3)$ & $<0.0001$ \\
\hline Body Mass Index $\left(\mathrm{Kg} / \mathrm{m}^{2}\right)$ & $28.6(5.5)$ & $29.9(5.6)$ & $27.2(5.1)$ & $<0.0001$ \\
\hline $\begin{array}{l}\text { Systolic blood pressure } \\
(\mathrm{mmHg})\end{array}$ & $136.2(16.8)$ & $146.9(14.2)$ & $124.2(9.9)$ & $<0.0001$ \\
\hline $\begin{array}{l}\text { Diastolic blood pressure } \\
(\mathrm{mmHg})\end{array}$ & $80.6(9.8)$ & $85.3(9.4)$ & $75.4(7.3)$ & $<0.0001$ \\
\hline Observed FVC (L) & $3.9(1.1)$ & $3.8(1.2)$ & $4.1(1.0)$ & $<0.0001$ \\
\hline Observed FEV $_{1}(\mathrm{~L})$ & $3.2(0.9)$ & $3.1(0.9)$ & $3.3(0.8)$ & $<0.0001$ \\
\hline
\end{tabular}

Table 2: Multivariate logistic regression analysis for the relationship between hypertension and lung function

\begin{tabular}{|c|c|c|}
\hline Variable & $\begin{array}{r}\text { Model 1-Using } \\
\text { linear } \\
\text { FVC }^{*}(\mathrm{~L}) \\
\text { OR }(95 \% \mathrm{CI})\end{array}$ & $\begin{array}{r}\text { Model 2- Using } \\
\text { linear } \\
\mathrm{FEV}_{1}{ }^{\#}(\mathrm{~L}) \\
\text { OR }(95 \% \mathrm{CI})\end{array}$ \\
\hline Age, in years & $1.06(1.05,1.07)$ & $1.06(1.05,1.07)$ \\
\hline Lung function: $\mathrm{X}$ & $0.95(0.82,1.11)$ & $0.99(0.83,1.21)$ \\
\hline BMI & $1.09(1.07,1.11)$ & $1.09(1.07,1.12)$ \\
\hline Sex (Reference is Male) & $0.46(0.34,0.63)$ & $0.49(0.37,0.66)$ \\
\hline $\begin{array}{l}\text { Parental history of blood } \\
\text { pressure (Reference is No) }\end{array}$ & $1.72(1.39,2.13)$ & $1.72(1.39,2.12)$ \\
\hline $\begin{array}{l}\text { Smoking status (Reference } \\
\text { is Non-smoker) }\end{array}$ & $1.23(0.89,1.69)$ & $1.24(0.90,1.70)$ \\
\hline
\end{tabular}

"Functional form of $\mathrm{FVC}=$ linear. ${ }^{*}$ Functional form of $\mathrm{FEV}_{1}=$ linear. 
Table 3: Deviance difference in comparison to a straight line for fractional polynomial $\mathrm{FVC}$ as a continuous predictor adjusting for other covariates

\begin{tabular}{|c|c|c|c|c|c|c|c|c|c|c|}
\hline \multicolumn{11}{|c|}{ Fractional polynomials } \\
\hline \multicolumn{2}{|c|}{ First Degree } & \multicolumn{9}{|c|}{ Second Degree } \\
\hline \multirow{2}{*}{$\begin{array}{c}\text { Power } \\
\text { p1 }\end{array}$} & \multirow{2}{*}{$\begin{array}{c}{ }^{\&} \text { Gain }= \\
\text { Deviance } \\
\text { difference }\end{array}$} & \multicolumn{2}{|c|}{ power } & \multirow{2}{*}{$\begin{array}{c}{ }^{\&} \text { Gain }= \\
\text { Deviance } \\
\text { difference }\end{array}$} & \multicolumn{2}{|c|}{ power } & \multirow{2}{*}{$\begin{array}{c}{ }^{\&} \text { Gain }= \\
\text { Deviance } \\
\text { difference }\end{array}$} & \multicolumn{2}{|c|}{ power } & \multirow{2}{*}{$\begin{array}{c}{ }^{\&} \text { Gain }= \\
\text { Deviance } \\
\text { difference }\end{array}$} \\
\hline & & $\mathrm{p} 1$ & $\mathrm{p} 2$ & & $\mathrm{p} 1$ & $\mathrm{p} 2$ & & $\mathrm{p} 1$ & $\mathrm{p} 2$ & \\
\hline-2 & 4.5552 & -2 & -2 & 5.6768 & -1 & 1 & 9.9606 & 0 & 2 & 14.9068 \\
\hline-1 & 4.8982 & -2 & -1 & 4.9092 & -1 & 2 & 11.8862 & 0 & 3 & 15.9202 \\
\hline-0.5 & 3.8900 & -2 & -0.5 & 4.5718 & -1 & 3 & 13.3666 & 0.5 & 0.5 & 13.3786 \\
\hline 0 & 2.4062 & -2 & 0 & 4.6656 & -0.5 & -0.5 & 8.0296 & 0.5 & 1 & 14.4184 \\
\hline 0.5 & 0.9686 & -2 & 0.5 & 5.1162 & -0.5 & 0 & 9.3500 & 0.5 & 2 & 15.8502 \\
\hline $1^{\#}$ & 0 & -2 & 1 & 5.8032 & -0.5 & 0.5 & 10.5976 & 0.5 & 3 & 16.5416 \\
\hline 2 & -0.1124 & -2 & 2 & 7.4908 & -0.5 & 1 & 11.7322 & 1 & 1 & 15.3398 \\
\hline \multirow[t]{5}{*}{3} & 1.3524 & -2 & 3 & 9.1552 & -0.5 & 2 & 13.5894 & 1 & 2 & 16.459 \\
\hline & & -1 & -1 & 5.7886 & -0.5 & 3 & 14.8708 & 1 & 3 & 16.7978 \\
\hline & & -1 & -0.5 & 6.7076 & 0 & 0 & 10.8090 & 2 & 2 & 16.8690 \\
\hline & & -1 & 0 & 7.7716 & 0 & 0.5 & 12.1050 & 2 & 3 & 16.4948 \\
\hline & & -1 & 0.5 & 8.8788 & 0 & 1 & 13.2206 & 3 & 3 & 15.4946 \\
\hline
\end{tabular}

${ }^{\&} \mathrm{Gain} \mathrm{G}=\mathrm{D}(1,1)-\mathrm{D}(m, \boldsymbol{p}) ; \mathrm{D}(1,1)=$ First degree fractional polynomial with power 1 (straight line), $\mathrm{D}(m=2, \boldsymbol{p})=$ Second degree fractional polynomial with power $\boldsymbol{p}$. Highest gain gives the better fit model. "Deviance of straight line model=2099.1298.

Table 4: Deviance difference in comparison to a straight line for fractional polynomial $\mathrm{FEV}_{1}$ as a continuous predictor adjusting for other covariates

\begin{tabular}{|c|c|c|c|c|c|c|c|c|c|c|}
\hline \multicolumn{11}{|c|}{ Fractional polynomials } \\
\hline \multicolumn{2}{|c|}{ First Degree } & \multicolumn{9}{|c|}{ Second Degree } \\
\hline Power & ${ }^{\&}$ Gain $=$ & \multicolumn{2}{|c|}{ power } & \multirow{2}{*}{$\begin{array}{c}{ }^{\&} \text { Gain }= \\
\text { Deviance } \\
\text { difference }\end{array}$} & \multicolumn{2}{|c|}{ power } & \multirow{2}{*}{$\begin{array}{l}{ }^{\&} \text { Gain }= \\
\text { Deviance } \\
\text { difference }\end{array}$} & \multicolumn{2}{|c|}{ power } & \multirow{2}{*}{$\begin{array}{c}{ }^{\&} \text { Gain= } \\
\text { Deviance } \\
\text { difference }\end{array}$} \\
\hline p1 & & $\mathrm{p} 1$ & p2 & & p1 & $\mathrm{p} 2$ & & $\mathrm{p} 1$ & p2 & \\
\hline-2 & 3.8254 & -2 & -2 & 3.9102 & -1 & 1 & 9.0674 & 0 & 2 & 13.2132 \\
\hline-1 & 3.2764 & -2 & -1 & 3.9066 & -1 & 2 & 10.9312 & 0 & 3 & 14.1484 \\
\hline-0.5 & 2.3112 & -2 & -0.5 & 4.2070 & -1 & 3 & 12.3296 & 0.5 & 0.5 & 11.6960 \\
\hline 0 & 1.1796 & -2 & 0 & 4.7276 & -0.5 & -0.5 & 7.1136 & 0.5 & 1 & 12.6470 \\
\hline 0.5 & 0.3174 & -2 & 0.5 & 5.4368 & -0.5 & 0 & 8.2380 & 0.5 & 2 & 14.0070 \\
\hline $1^{\#}$ & 0 & -2 & 1 & 6.2802 & -0.5 & 0.5 & 9.3502 & 0.5 & 3 & 14.6376 \\
\hline 2 & 0.9828 & -2 & 2 & 8.1122 & -0.5 & 1 & 10.4018 & 1 & 1 & 13.4862 \\
\hline \multirow[t]{5}{*}{3} & 3.0190 & -2 & 3 & 9.7638 & -0.5 & 2 & 12.1754 & 1 & 2 & 14.5534 \\
\hline & & -1 & -1 & 5.1610 & -0.5 & 3 & 13.3714 & 1 & 3 & 14.8584 \\
\hline & & -1 & -0.5 & 6.0316 & 0 & 0 & 9.4476 & 2 & 2 & 14.9678 \\
\hline & & -1 & 0 & 7.0090 & 0 & 0.5 & 10.5858 & 2 & 3 & 14.6304 \\
\hline & & -1 & 0.5 & 8.0392 & 0 & 1 & 11.6106 & 3 & 3 & 13.7522 \\
\hline
\end{tabular}

${ }^{8} \mathrm{Gain} \mathrm{G}=\mathrm{D}(1,1)-\mathrm{D}(m, \boldsymbol{p}) ; \mathrm{D}(1,1)=$ First degree fractional polynomial with power 1 (straight line), $\mathrm{D}(m=2, \boldsymbol{p})=$ Second degree fractional polynomial with power $\boldsymbol{p}$. Highest gain gives the better fit model. "Deviance of straight line model=2099.4704. 
Table 5: Multivariate fractional polynomial logistic regression analysis for the relationship between hypertension and lung function

\begin{tabular}{|c|c|c|}
\hline & $\begin{array}{l}\text { Model 3-Using } \\
\text { quadratic fractional } \\
\text { polynomials for } \\
\text { FVC }^{*}(\mathrm{~L})\end{array}$ & $\begin{array}{l}\text { Model 4- Using } \\
\text { quadratic fractional } \\
\text { polynomials for } \\
\mathrm{FEV}_{1}{ }^{\#}(\mathrm{~L})\end{array}$ \\
\hline Variable & OR $(95 \% \mathrm{CI})$ & OR $(95 \% \mathrm{CI})$ \\
\hline Age, in years & $1.05(1.04,1.06)$ & $1.06(1.04,1.07)$ \\
\hline \multirow{2}{*}{$\begin{aligned} \text { Lung function: } & X^{2} \\
& X^{2} \log (X)\end{aligned}$} & $0.72(0.61,0.85)$ & $0.68(0.55,0.84)$ \\
\hline & $1.17(1.08,1.27)$ & $1.24(1.11,1.39)$ \\
\hline BMI & $1.09(1.07,1.11)$ & $1.09(1.07,1.11)$ \\
\hline Sex (Reference is Male) & $0.42(0.31,0.58)$ & $0.48(0.35,0.64)$ \\
\hline $\begin{array}{l}\text { Parental history of blood } \\
\text { pressure (Reference is No) }\end{array}$ & $1.76(1.42,2.18)$ & $1.76(1.42,2.18)$ \\
\hline $\begin{array}{l}\text { Smoking status (Reference } \\
\text { is Non-smoker) }\end{array}$ & $1.20(0.87,1.65)$ & $1.21(0.88,1.66)$ \\
\hline
\end{tabular}

${ }^{*}$ Functional form of $\mathrm{FVC}=(\mathrm{FVC})^{2}+(\mathrm{FVC})^{2} \ln (\mathrm{FVC})$.

${ }^{\#}$ Functional form of $\mathrm{FEV}_{1}=\left(\mathrm{FEV}_{1}\right)^{2}+\left(\mathrm{FEV}_{1}\right)^{2} \ln \left(\mathrm{FEV}_{1}\right)$.

Table 6: Logistic Regression Analysis for the relationship between hypertension and lung function- Crude odds ratios (OR) and 95\% confidence intervals $(95 \% \mathrm{CI})$

\begin{tabular}{|c|c|c|}
\hline & Male $\mathrm{n}=798$ & Female $n=1036$ \\
\hline & OR $(95 \% \mathrm{CI})$ & OR $(95 \% \mathrm{CI})$ \\
\hline FVC (L) & $0.67(0.57,0.78)$ & $0.33(0.27,0.41)$ \\
\hline $\mathrm{FEV}_{1}(\mathrm{~L})$ & $0.62(0.52,0.74)$ & $0.29(0.23,0.36)$ \\
\hline
\end{tabular}


Table 7: Logistic Regression Analysis for the relationship between hypertension and lung function stratified by gender- Adjusted odds ratios and 95\% confidence intervals (95\% CI), Adjusted for age, body mass index, parental history of blood pressure, and smoking

\begin{tabular}{|c|c|c|}
\hline Variable & $\begin{array}{c}\text { FVC }(\mathrm{L}) \\
\text { OR }(95 \% \mathrm{CI})\end{array}$ & $\begin{array}{c}\mathrm{FEV}_{1}(\mathrm{~L}) \\
\mathrm{OR}(95 \% \mathrm{CI})\end{array}$ \\
\hline \multicolumn{3}{|l|}{ (a) Males (n=798) } \\
\hline Age, in years & $1.05(1.04,1.07)$ & $1.06(1.04,1.07)$ \\
\hline Lung function & $1.10(0.90,1.33)$ & $1.15(0.91,1.46)$ \\
\hline BMI & $1.09(1.05,1.13)$ & $1.09(1.05,1.13)$ \\
\hline $\begin{array}{l}\text { Parental history of blood } \\
\text { pressure (Reference is No) }\end{array}$ & $1.33(0.97,1.83)$ & $1.34(0.98,1.83)$ \\
\hline $\begin{array}{l}\text { Smoking status (Reference is } \\
\text { Non-smoker) }\end{array}$ & $1.37(0.88,2.15)$ & $1.40(0.89,2.19)$ \\
\hline \multicolumn{3}{|l|}{ (b) Females $(n=1036)$} \\
\hline Age, in years & $1.06(1.04,1.07)$ & $1.06(1.04,1.07)$ \\
\hline Lung function & $0.73(0.56,0.95)$ & $0.75(0.55,1.02)$ \\
\hline BMI & $1.09(1.06,1.11)$ & $1.09(1.06,1.12)$ \\
\hline $\begin{array}{l}\text { Parental history of blood } \\
\text { pressure (Reference is No) }\end{array}$ & $2.16(1.61,2.88)$ & $2.14(1.60,2.86)$ \\
\hline $\begin{array}{l}\text { Smoking status (Reference is } \\
\text { Non-smoker) }\end{array}$ & $1.05(0.66,1.68)$ & $1.05(0.66,1.67)$ \\
\hline
\end{tabular}

OR: Odds ratio CI: Confidence Interval 


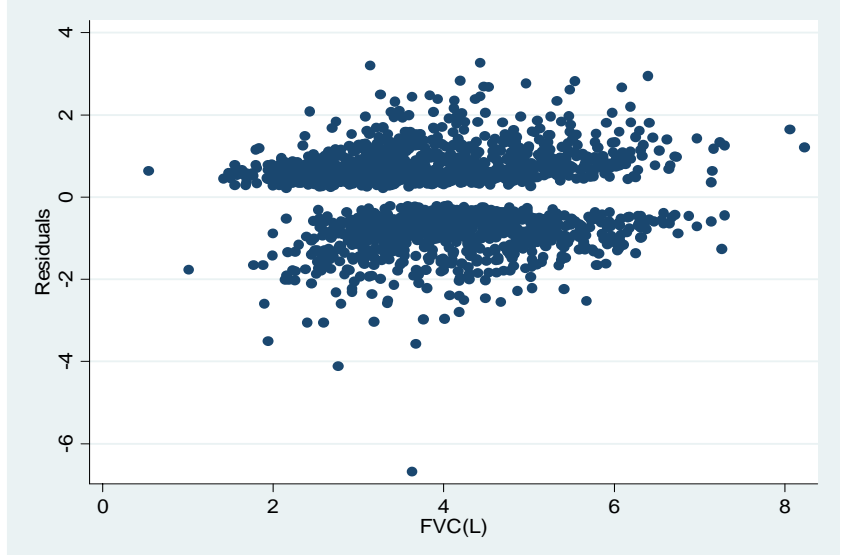

Figure 1: Plot of residuals verses FVC values (considering linear form) adjusted for covariates

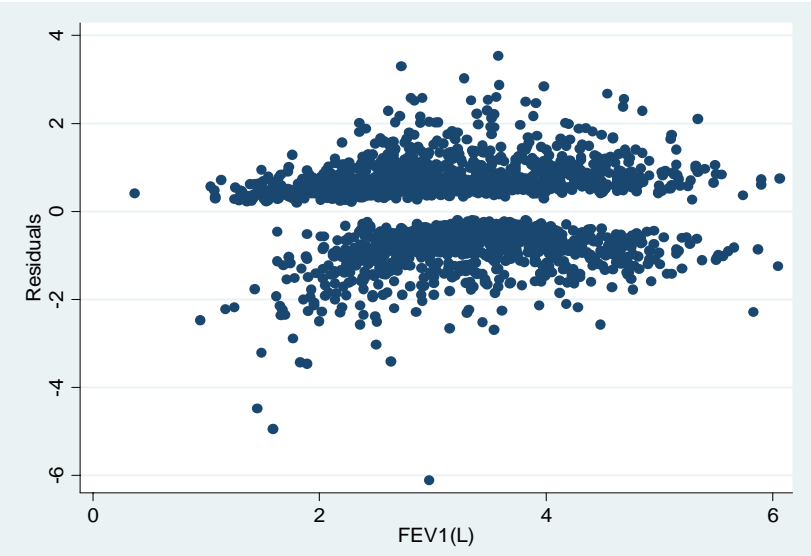

Figure 2: Plot of residuals verses $\mathrm{FEV}_{1}$ values (considering linear form) adjusted for covariates 


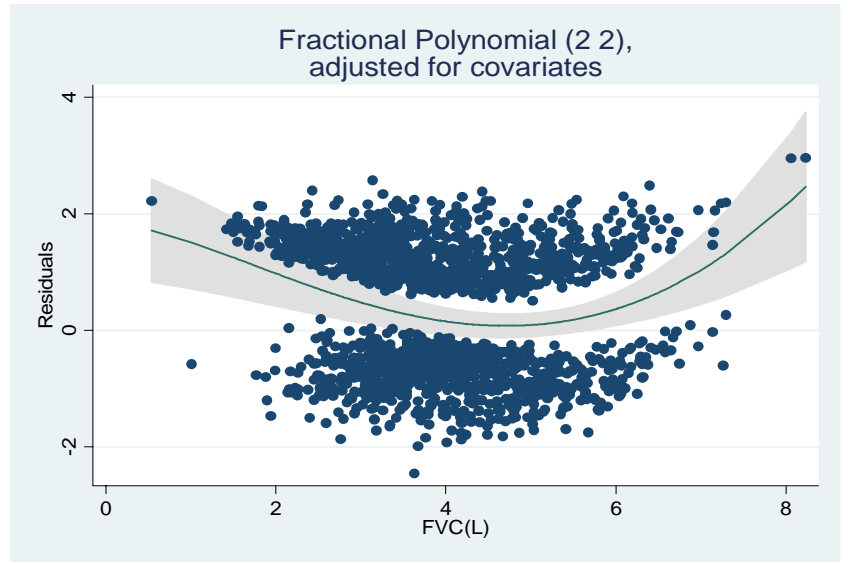

Figure 3: Plot of residuals verses FVC values (considering fractional polynomial $(2,2)$ form) adjusted for covariates

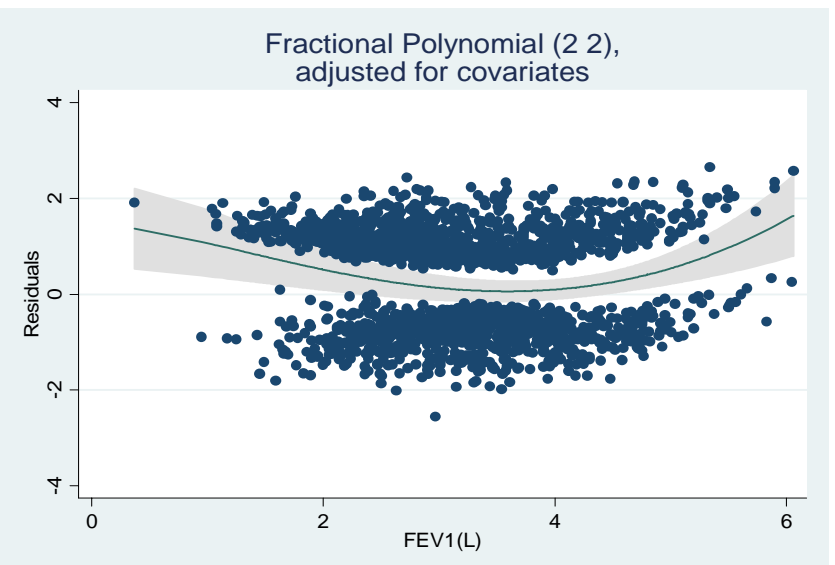

Figure 4: Plot of residuals verses $\mathrm{FEV}_{1}$ values (considering fractional polynomial $(2,2)$ form) adjusted for covariates 


\section{References:}

1. Vasan, R. S., Larson, M. G., Leip, E. P., Evans, J. C., O’Donnell, C. J., Kannel, W. B. and Levy, D. Impact of High-Normal Blood Pressure on the Risk of Cardiovascular Disease. The New England Journal of Medicine, 345(18), 1291-1297, 2001.

2. Tockman, M. S., Pearson, J.D., Fleg, J. L., Metter, E. J., Kao, S.Y., Rampal, K. G., Cruise, L. J. and Fozard, J. L. Rapid decline in $\mathrm{FEV}_{1}$. A new risk factor for coronary heart disease mortality. American Journal of Respiratory \& Critical care Medicine, 151(2), 390-398, 1995.

3. Beaty, T. H., Cohen, B. H., Newill, C. A., Diamond, E. L. and Chen, C. J. Impaired pulmonary function as a risk factor as a risk factor for mortality. American Journal of Epidemiology, 116, 102113, 1982.

4. Marcus, E. B., Curb, J. D., MacLean, C. J., Reed, D. M. and Yano, K. (1989). Pulmonary function as a predictor of coronary heart disease. American Journal of Epidemiology, 129, 97-104.

5. Strachan, D. P. (1991). Ventilatory function as a predictor of fatal stroke. British Medical Journal, 302, 84-87.

6. Selby, J. V., Friedman, G. D. and Quesenberry, C. P. (1990). Precursors of Essential Hypertension: Pulmonary Function, Heart Rate, Uric Acid, Serum Cholesterol, and other serum chemistries. American Journal of Epidemiology, 131(6), 1017-1027.

7. Sparrow, D., Weiss, S. T., Vokonas, P. S., Cupples, L. A., Ekerdt, D. J. and Colton, T. (1988). Forced Vital Capacity and the risk of hypertension. American Journal of Epidemiology, 127(4), 734741.

8. Engström, G., Hedblad, B., Valind, S. and Janzon, L. (2001). Increased incidence of myocardial infraction and stroke in hypertensive men with reduced lung function. Journal of Hypertension, 19, 295-301.

9. Schnabel, E., Karrasch, S., Schulz, H., Gläser, S., Meisinger, C., Heier, M., Peters, A., Wichmann, H-E, Behr, J., Huber, R. M. and 
Heinrich, J., for the Cooperative Health research in the Region of Augsberg (KORA) Study Group. (2011). High blood pressure, antihypertensive medication and lung function in a general adult population. Respiratory research, 12: 50. Accessed on July 10, 2011. Available from [http://respiratoryresearch.com/content/12/1/50].

10. Fabbri, L. M. and Rabe, K. (2007). From COPD to chronic systemic inflammatory syndrome?. Lancet, 370, 797-799.

11. Kalhan, R., Tran, B. T., Colangelo, L. A., Rosenberg, S. R., Liu, K., Thyagarajan, B., Jacobs, D. R. and Smith, L. J. (2010). Systemic Inflammation in Young Adults Is Associated with Abnormal Lung Function in Middle Age. PLoS ONE, 5(7):e11431, doi:10.1371/journal.pone.0011431.

12. Margretardottir, O. B., Thorieifsson, S. J., Gudmundsson, G., Olafsson, I., Benediktsdottir, B., Janson, C., Buist, A. S. and Gislason, T. (2009). Hypertension, Systemic Inflammation and Body weight in Relation to Lung Function Impairment-An Epidemiological Study. COPD, 6, 250-255.

13. Gracia-Rio, F., Miravitlles, M., Soriano, J. B., Muñoz, L., DuranTauleria, E., Sánchez, G., Sobradillo, V., Ancochea, J. and EPISCAN Steering Committee. (2011). Systemic inflammation in chronic obstructive pulmonary disease: a population-based study. Respiratory research, 11:63. Accessed on July 12, 2011. Available from [http://respiratory-research.com/content/11/1/63].

14. Kahn, H. A., Medalie, J. H., Neufeld, H. N., Riss, E. and Goldbourt, U. (1972). The incidence of hypertension and associated factors: the Israel ischemic heart disease study. American Heart Journal, 84(2), 171-182.

15. Weissfeld, J. L. and Kuller, L. H. (1985). Methodologic evaluation of incidence rates for hypertension: calculated for Pittsburgh's MRFIT usual care men. Journal of Chronic Disease, 38, 915-925.

16. Garrison, R. J., Kannel, W. B., Stokes, J., III and Castelli, W. P. (1987). Incidence and precursors of hypertension in young adults: 
the Framingham Offspring Study. Preventive Medicine, 16(2), 235-251.

17. Chen, Y., Rennie, D. C., Cormier, Y. and Dosman, J. (2005). Sex specificity of asthma associated with objectively measured body mass index and waist circumference: The Humboldt Study. Chest, 128, 3048-3054.

18. Canadian Coalition for High Blood Pressure. Prevention and control. Guidelines for the measurement of blood pressure. 1988.

19. Chen, Y., Rennie, D. C., Lockinger, L. A. and Dosman, J. A. (1998). Association between obesity and high blood pressure: reporting bias related to gender and age. International Journal of Obesity, 22, 771-777.

20. Standardization of Spirometry-1994 update. American Thoracic Society. (1995). American Journal of Respiratory and Critical Care Medicine, 152, 1107-1646.

21. Hosmer, D. W. and Lemshow, S. (1989). Applied Logistic Regression. A Wiley-Interscience Publication, John Wiley and Sons Inc.: Canada, 82-134.

22. Royston P, Altman DG. Regression using fractional polynomials of continuous covariates: parsimonious parametric modelling (with Discussion). Applied Statistics 1994; 43(3):429-467.

23. Sauerbrei, W., Meier-Hirmer, C., Benner, A. and Royston, P. (2006). Multivariable regression model building by using fractional polynomials: description of SAS, STATA and R programs. Computational Statistics and Data Analysis, 50, 3464 3485 .

24. Royston, P. and Sauerbrei, W. (2008). Multivariable ModelBuilding: A Pragmatic Approach to Regression Analysis Based on Fractional Polynomials for Continuous Variables. Wiley: New York.

25. Stamler, J., Stamler, R. and Neaton, J. D. (1993). Blood pressure, systolic and diastolic, and cardiovascular risks: US population data. Archives of Internal Medicine, 153, 598-615. 
26. Kannel, W. B., Seidman, J. M., Fercho, W. and Castelli, W. P. (1974). Vital capacity and congestive heart failure: the Framing study. Circulation, 49, 1160-1166.

27. Lee, J. Y., Ahn, S. V., Choi, D. P., Suh, M., Kim, H. C., Kim, Y. S. and Suh, I. (2009). Association between Hypertension and Pulmonary Function in Rural Adults in Korea. Journal of Preventive Medicine and Public Health, 42(1), 21-28.

28. Wu, Y., Vollmer, W. M., Buist, A. S., Tsai, R., Cen, R., Wu, X., Chen, P., Li, Y., Guo, C., Mai, J. and Davis, C. E. (1998). Relationship between lung function and blood pressure in Chinese men and women of Beijing and Guangzhou. International Journal of Epidemiology, 27, 49-56.

29. Engström, G., Wollmer, P., Valind, S., Hedblad, B. and Janzon, L. (2001). Blood pressure increase between 55 and 68 years of age is inversely related to lung function: longitudinal results from the cohort study 'Men born in 1914'. Journal of Hypertension, 19, 1203-1208.

30. Stamler, R., Liu, L. S., Nichols, R., Huang, D. X., Long, Z. P., Xie, J. X. and Elliott, P. (1993). Blood pressure and life style in the People's Republic of China: three samples in the INTERSALT Study. Journal of Human Hypertension, 7, 429-35.

31. Chaswal, M., Singh, S., Tandon, O. P. and Shankar, N. (1998). A study of pulmonary profile of hypertensive patients-comparison of atenolol vs amlodipine. Indian Journal of Physiology \& Pharmacology, 42(4), 538-542.

32. Dalton, M., Cameron, A. J., Zimmet, P. Z., Shaw, J. E., Jolley, D., Dunstan, D. W., Welborn, T. A. (2003). Waist circumference, waist-hip ratio and body mass index and their correlation with cardiovascular disease risk factors in Australian adults. Journal of Internal Medicine, 254, 555-563.

33. Stevens, J., Gautam, S. P. and Keil, J. E. (1993). Body Mass Index and Fat Patterning as Correlates of Lipids and Hypertension in an Elderly, Biracial Population. Journal of Gerontology: Medical Sciences, 48, M249-M254. 
34. Friedman, G. D., Selby, J. V., Quesenberry, C. P., Armstrong, M. A. and Klatsky, A. L. (1988). Precursors of Essential Hypertension: Body Weight, Alcohol and Salt Use, and Parental History of Hypertension. Preventive Medicine, 17, 387-402.

35. Kannel, W. B. (1996). Blood pressure as a cardiovascular risk factor: prevention and treatment. Journal of the American Medical Association, 275, 1571-1576. 
